\title{
Effects of ambient temperature, airspeed, and wind direction on heat transfer coefficient for the human body by means of manikin experiments and CFD analysis
}

\author{
Shan $\mathrm{Gao}^{1, *}$, Ryozo Ooka ${ }^{2}$, and Wonseok $\mathrm{Oh}^{1}$ \\ ${ }^{1}$ Graduate School of Engineering, Department of Architecture, The University of Tokyo, Japan \\ ${ }^{2}$ Institute of Industrial Science, The University of Tokyo, 4 -6 -1 Komaba, Meguro-ku,Tokyo, 153-8505,Japan
}

\begin{abstract}
The purpose of this study is to confirm the effect of ambient temperature, airspeed, and wind direction on the heat transfer around the human body. A fixed surface temperature $\left(33^{\circ} \mathrm{C}\right)$ thermal manikin (TM) with 16 segments was employed. First, the manikin was placed in a climate chamber with ambient temperatures of $20{ }^{\circ} \mathrm{C}, 24{ }^{\circ} \mathrm{C}$, and $28{ }^{\circ} \mathrm{C}$, at airspeeds of less than $0.1 \mathrm{~m} / \mathrm{s}$ to represent calm condition. Higher ambient temperatures led to a decrease in the convective heat transfer coefficient. The convective heat transfer coefficients for the sitting posture were higher than those of the standing posture. The same TM was then put in a wind tunnel with airspeeds ranging from $0.25 \mathrm{~m} / \mathrm{s}$ to $1.4 \mathrm{~m} / \mathrm{s}$ to represent forced convection. The TM was set to face upwind, downwind, and perpendicular to the wind (i.e., its right side facing the wind). Regression models for the convective heat transfer coefficient and airspeed for different wind directions and postures were derived. In contrast to the calm condition, the convective heat transfer coefficients for the sitting posture were lower than those for the standing posture. The convective heat transfer coefficients for the standing posture were largest when the TM was facing downwind, and smallest when the right side of the TM was facing the wind. To verify the results of the experiment, computational fluid dynamics (CFD) analysis was performed with conditions matching those of the experiment by using a computational TM with the same shape as that used in the experiment. The boundary conditions of the CFD analysis were set from the experiment. The CFD analysis results were consistent with the experimental data.
\end{abstract}

\section{Introduction}

Thermal comfort, which is judged through cognitive processes influenced by physical, physiological, psychological, and other factors [1], has been evaluated in many studies. Höppe [2] discussed the difference between assessing indoor and outdoor thermal comfort. Fanger et al. [3] revealed comfort limits for asymmetric thermal radiation. Such works have identified the thermal properties - such as convective heat transfer coefficient, radiative heat transfer coefficient, and equivalent temperature — of individual body parts as key parameters for predicting thermal comfort.

The development of realistic-looking thermal manikins (TMs) has facilitated acquisition of the aforementioned key parameters. Tanabe et al. [4] described a method for measuring non-uniform thermal environments using a TM with a controlled skin surface temperature and defined a manikin-based equivalent temperature. De Dear et al. [5] calculated the convective and radiative heat transfer coefficients for different human body parts with a 16-segment TM under a wide range of wind speeds and directions through experiments.

In recent years, computational fluid dynamics (CFD) has become an important tool in the prediction of thermal comfort, with the ability to predict temperature and velocity fields cheaply and quickly compared to experimental work [6]. Much work on CFD calculations with computational TMs (CTMs) has been performed in Japan (University of Tokyo) and Denmark (Aalborg University and the Technical University of Denmark). Ono et al. [7] verified the accuracy of CFD analysis in the field of heat transfer around the human body. They measured the convective heat transfer coefficient for the human body in an outdoor environment by means of a wind tunnel test and CFD analysis. However, only the standing posture facing upwind with airspeeds ranging from $0.5 \mathrm{~m} / \mathrm{s}$ to $2.0 \mathrm{~m} / \mathrm{s}$ was researched. Yang et al. [8] developed regression equations for the convective heat transfer coefficient according to the temperature difference between skin and the environment; however, the temperature difference was acquired from the change of skin temperature, not the ambient temperature. Fanger's PMV model (i.e., $h_{c}=2.38\left(t_{c l}-t_{a}\right)^{0.25}$ ) provides a widely accepted regression equations for the convective heat transfer coefficient according to the temperature difference between skin and the environment, but this is at the whole-body level [5]. Clothing is also an important factor that affects thermal comfort. Lu et al. [9] performed $486 \mathrm{TM}$ tests to confirm

\footnotetext{
* Corresponding author: gaoshan@iiis.u-tokyo.ac.jp
} 
the effects of air velocity and walking speed on total clothing insulation. Oguro et al. [10] evaluated the convective heat transfer coefficients for each part of the clothed human body under different conditions.

To the best of our knowledge, few reports comprehensively describe how the micro-climate, such as ambient temperature, airspeed, and wind direction, affects human body heat transfer for different postures by means of both CFD analysis and manikin experiments. This research aims at confirming the effect of ambient temperature, airspeed, and wind direction on heat transfer around the human body by means of experimentation and CFD analysis. Further work regarding the effect of clothing is in progress.

\section{Estimation of convective heat transfer coefficient}

Heat dissipates from the body to the immediate surroundings through several models of heat exchange [1]:

$$
\begin{gathered}
M-W=\left(C+R+E_{s k}\right)+\left(C_{r e s}+E_{r e s}\right) \\
+\left(S_{s k}+S_{c r}\right)
\end{gathered}
$$

$M$ : Rate of metabolic heat production, $\mathrm{W} / \mathrm{m}^{2}$

$W$ : Rate of mechanical work accomplished, $\mathrm{W} / \mathrm{m}^{2}$

$C$ : Convective heat loss from skin, $\mathrm{W} / \mathrm{m}^{2}$

$R$ : Radiative heat loss from skin, $\mathrm{W} / \mathrm{m}^{2}$

$C+R$ : Sensible heat loss from skin (Total heat loss),

$\mathrm{W} / \mathrm{m}^{2}$

$E_{s k}$ : Total rate of evaporative heat loss from skin, $\mathrm{W} / \mathrm{m}^{2}$

$C_{r e s}$ : Rate of convective heat loss from respiration, $\mathrm{W} / \mathrm{m}^{2}$

$E_{\text {res }}:$ Rate of evaporative heat loss from respiration, $\mathrm{W} / \mathrm{m}^{2}$

$S_{s k}$ : Rate of heat storage in skin, $\mathrm{W} / \mathrm{m}^{2}$

$S_{c r}$ : Rate of heat storage in core, $\mathrm{W} / \mathrm{m}^{2}$

In this paper, only sensible heat transfer was taken into consideration:

$$
q_{t, i}=C+R=q_{c, i}+q_{r, i}
$$

$q_{t, i}$ : Sensible heat loss (Total heat loss) through the skin of manikin segment $i, \mathrm{~W} / \mathrm{m}^{2}$

$q_{c, i}$ : Convective heat loss through the skin of manikin segment $i, \mathrm{~W} / \mathrm{m}^{2}$

$q_{r, i}$ : Radiative heat loss through the skin of manikin segment $i, \mathrm{~W} / \mathrm{m}^{2}$

Therefore, convective heat transfer coefficient and radiative heat transfer coefficient can respectively be calculated as:

$$
q_{c, i}=h_{c, i}\left(t_{s, i}-t_{a}\right)
$$

$h_{c, i}$ : Convective heat transfer coefficient for body segment $i, \mathrm{~W} /\left(\mathrm{m}^{2} \cdot \mathrm{K}\right)$

$t_{s, i}:$ Skin temperature of manikin segment $i,{ }^{\circ} \mathrm{C}$ $t_{a}:$ Air temperature, ${ }^{\circ} \mathrm{C}$;

and

$$
q_{r, i}=h_{r, i}\left(t_{s, i}-\overline{t_{w}}\right) .
$$

$h_{r, i}$ : Radiative heat transfer coefficient for body segment $i, \mathrm{~W} /\left(\mathrm{m}^{2} \cdot \mathrm{K}\right)$

$\overline{t_{w}}$ : Mean wall temperature (Chamber or wind tunnel), ${ }^{\circ} \mathrm{C}$

\section{Methods}

\subsection{Experimental setup}

The experiment was divided into two parts: first, the manikin was placed in a climate chamber with ambient temperatures of $20^{\circ} \mathrm{C}, 24^{\circ} \mathrm{C}$, and $28^{\circ} \mathrm{C}$, at airspeeds of less than $0.1 \mathrm{~m} / \mathrm{s}$ to represent calm condition. Second, the same TM was then put in a wind tunnel with airspeeds ranging from $0.25 \mathrm{~m} / \mathrm{s}$ to $1.4 \mathrm{~m} / \mathrm{s}$ to represent forced convection.

\subsubsection{Thermal manikin (TM)}

Manikins are primarily used in the assessment of thermal comfort in automotive, indoor, and outdoor environments. The TM used in this research (shown in Fig. 1) has the shape of a female body, with 16 independent body segments. The skin surface temperature was fixed at $33{ }^{\circ} \mathrm{C}$, and the total heat loss from the TM was obtained by recording the power consumed by each segment to maintain the surface temperature. The TM can be situated into many postures owing to joints between different segments. In this study, the sitting and standing postures were adopted because they are the most common in indoor environments.

For the sitting posture, the manikin was seated on a mesh chair to minimize the impact on the airflow and radiation heat exchange around the manikin. This choice was made for consistency with CFD analysis, as the geometric shape of the chair is very difficult to accurately model, and its inclusion would cause additional computational burden. For the standing posture, the manikin was tied to the ceiling with a rope. For both postures, the feet of manikin were elevated 5 $\mathrm{cm}$ from the floor to eliminate conductive heat loss.

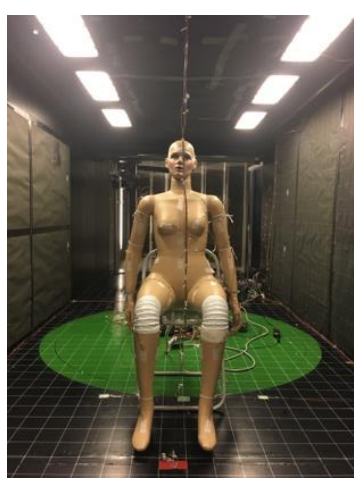

(a) Sitting posture

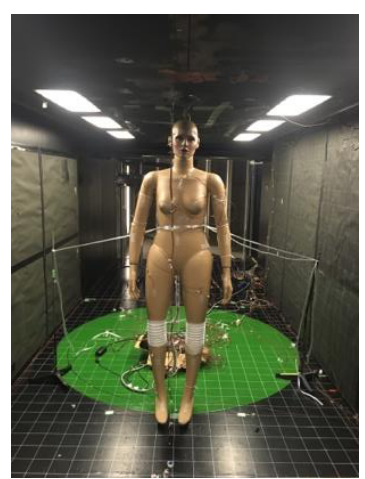

(b) Standing posture 


\subsubsection{Calm condition}

Fig. 2 shows a diagram of the climate chamber $(3.0 \mathrm{~m} \times$ $3.5 \mathrm{~m} \times 2.5 \mathrm{~m})$ in Institute of Industrial Science, the University of Tokyo. The TM was placed in the center of the climate chamber. The air temperature was set to $20{ }^{\circ} \mathrm{C}, 24^{\circ} \mathrm{C}$, and $28^{\circ} \mathrm{C}$ in order to confirm the effect of ambient temperature on the heat transfer coefficient. Air uniformly flowed in from the floor and out through the ceiling at airspeeds under $0.1 \mathrm{~m} / \mathrm{s}$. Air temperature was measured at two positions: mean air temperature, $t_{a}$, and air temperature near each body segment, $t_{a(s)}$. The horizontal position of $t_{a}$ was at point 't' in Fig. 2(a), and the vertical position was $0.1 \mathrm{~m}, 0.6 \mathrm{~m}, 1.1 \mathrm{~m}$, and $1.7 \mathrm{~m}$ (ISO) from the floor [11]. The horizontal positions of $t_{a(s)}$ are at points 'f', 'b', 'l', and 'r' in Fig. 2(a), and the vertical positions are shown in Fig. 2(b) and (c). When calculating the convective heat transfer coefficient, both $t_{a}$ and $t_{a(s)}$ were taken as reference temperatures. Wall temperature was measured at the center of each wall. Both wall temperature and air temperature were measured with T-type thermocouples. Temperatures were recorded over a period of $10 \mathrm{~min}$ at 10 -s intervals and averaged. The temperature profile is shown in Fig. 3. Airspeed was measured on the left and right sides of TM to confirm the uniformity of the air environment.

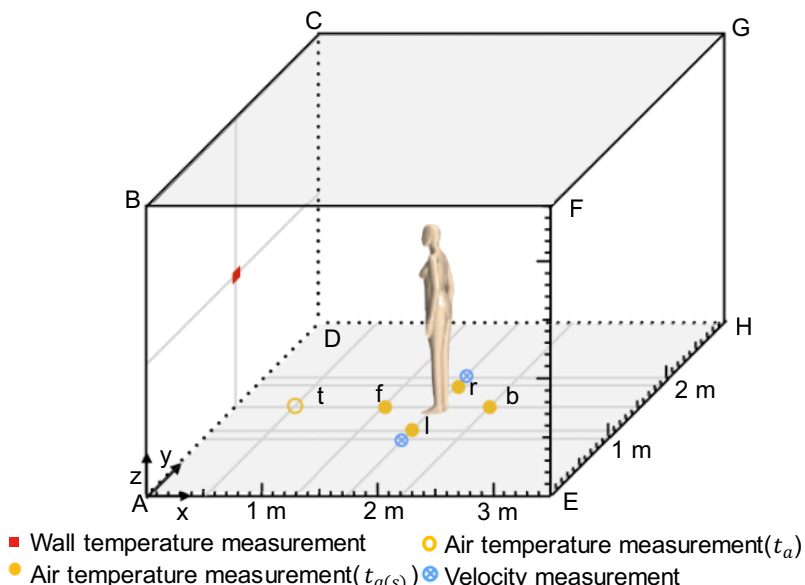

- Air temperature measurement $\left(t_{a(s)}\right) \otimes$ Velocity measurement

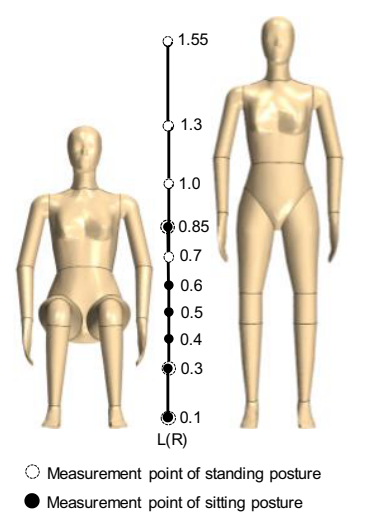

(b) (a)

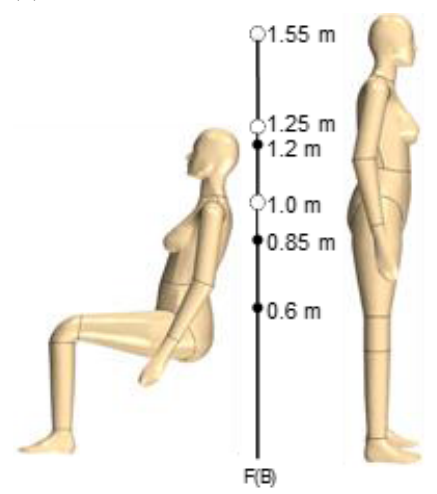

(c)
Fig. 2 Diagram of climate chamber experiments

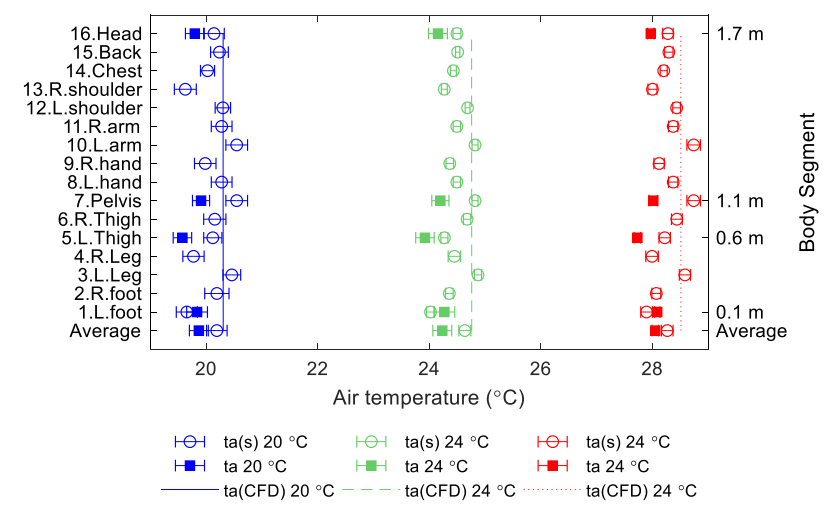

Fig. 3 Temperature profile of the chamber

$t_{a(s)}$ : Air temperature near each body segment

$t_{a}$ : Air temperature (ISO) $1.5 \mathrm{~m}$ from the TM

$t_{a(C F D)}$ : Air temperature near each body segment according to CFD analysis

\subsubsection{Forced convection}

Fig. 4 shows a diagram of the temperature stratification wind tunnel $(16.5 \mathrm{~m} \times 2.2 \mathrm{~m} \times 1.8 \mathrm{~m})$ located in Institute of Industrial Science, the University of Tokyo. Wind speeds of $0.25 \mathrm{~m} / \mathrm{s}, 0.75 \mathrm{~m} / \mathrm{s}, 1.1 \mathrm{~m} / \mathrm{s}, 1.4 \mathrm{~m} / \mathrm{s}$ were reproduced, which are in the range of expected indoor wind speeds, to confirm the effect of airspeed on the convective heat transfer coefficient. This wind tunnel can only reproduce stable wind at a minimum speed of 0.25 $\mathrm{m} / \mathrm{s}$. The TM was rotated between three positions such that the wind flowed from the front side, back side, and right side of the TM to confirm the effect of wind direction on the convective heat transfer coefficient. The air temperature in the wind tunnel cannot be controlled, however, the natural temperature in the wind tunnel was stable. For the sitting posture experiment, the air temperature in the wind tunnel was kept at $27.5{ }^{\circ} \mathrm{C} \pm$ $0.1{ }^{\circ} \mathrm{C}$ and the wall temperature was maintained at $27.5{ }^{\circ} \mathrm{C} \pm 0.1{ }^{\circ} \mathrm{C}$. For the standing posture experiment, the air temperature in the wind tunnel was kept at $27.1^{\circ} \mathrm{C}$ $\pm 0.1{ }^{\circ} \mathrm{C}$ and the wall temperature was maintained at $27.0^{\circ} \mathrm{C} \pm 0.1{ }^{\circ} \mathrm{C}$. The distribution of radiation was made uniform by pasting black paper to styrene board placed $0.01 \mathrm{~m}$ from the side walls of the wind tunnel. The ceiling was also pasted by black paper, and the lights were turned off during the experiment.

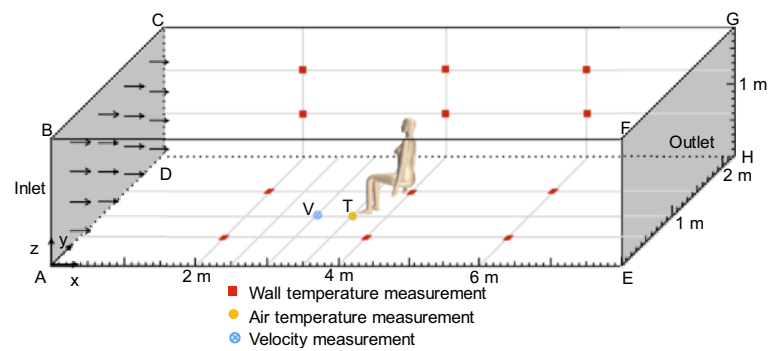

Fig. 4 Diagram of wind tunnel experiments

There were six temperature measurement points on each wall other than the inlet and outlet. The positions of measurement points on wall AEFB in Fig. 4 was the same as those wall DHGC, and the position of 
measurement point of wall BFGC (i.e., the ceiling) was the same as wall AEHD (i.e., the floor). The wall temperature distribution was uniform in the wind tunnel. The air temperature and velocity were separately measured $0.5 \mathrm{~m}$ and $1 \mathrm{~m}$ before the manikin at heights of $0.05 \mathrm{~m}, 0.1 \mathrm{~m}, 0.3 \mathrm{~m}, 0.4 \mathrm{~m}, 0.5 \mathrm{~m}, 0.6 \mathrm{~m}, 0.7 \mathrm{~m}, 0.85 \mathrm{~m}$, $1.0 \mathrm{~m}, 1.2 \mathrm{~m}, 1.25 \mathrm{~m}$, and $1.55 \mathrm{~m}$, which are the heights of the 16 segments of the TM during sitting and standing postures, as shown in Table 1.

Table 1 Heights of measurement points

\begin{tabular}{ccc}
\hline Segment & Sitting $(\mathbf{m})$ & Standing $(\mathbf{m})$ \\
\hline 10. Head & 1.2 & 1.55 \\
9. Back & 0.85 & 1.25 \\
8. Chest & 0.85 & 1.25 \\
7. Shoulder & 0.85 & 1.3 \\
6. Arm & 0.6 & 1.0 \\
5. Hand & 0.4 & 0.7 \\
4. Pelvis & 0.6 & 1.0 \\
3. Thigh & 0.5 & 0.7 \\
2. Leg & 0.3 & 0.3 \\
1. Foot & 0.1 & 0.1 \\
\hline
\end{tabular}

Both wall temperature and air temperature were measured with T-type thermocouples recording over a period of $10 \mathrm{~min}$ at 10 -s intervals and averaged. Air velocity was measured with a single-sensor miniature wire probe calibrated just prior to the experiment. The probe was suspended in the air stream by a programmable traverse system, enabling automatic wind speed profiles from floor to ceiling to be determined. The traverse system was programmed to stop for $90 \mathrm{~s}$ at equally spaced heights, and 1000 velocity data were recorded in $1 \mathrm{~s}$. In order to avoid the influence of the movement of the probe and traversing system, data recording was started $10 \mathrm{~s}$ after reaching the specified height. The velocity and turbulence profiles are shown in Fig. 5. The airspeeds below $0.3 \mathrm{~m}$ and above $1.2 \mathrm{~m}$ from the floor were smaller than other heights owing to the roughness of the floor and ceiling surface, underlining the importance of utilizing the actual airspeed profile near the different segments of the manikin. As for the turbulence intensity, smaller airspeeds resulted in greater turbulence intensity. The turbulence intensity near the ceiling and floor was much higher at all airspeeds. Except for the minimum airspeed of $0.25 \mathrm{~m} / \mathrm{s}$ - whose turbulence intensity was much higher, i.e., $4-14 \%$ - the difference between the turbulence intensities of the airspeeds was small.

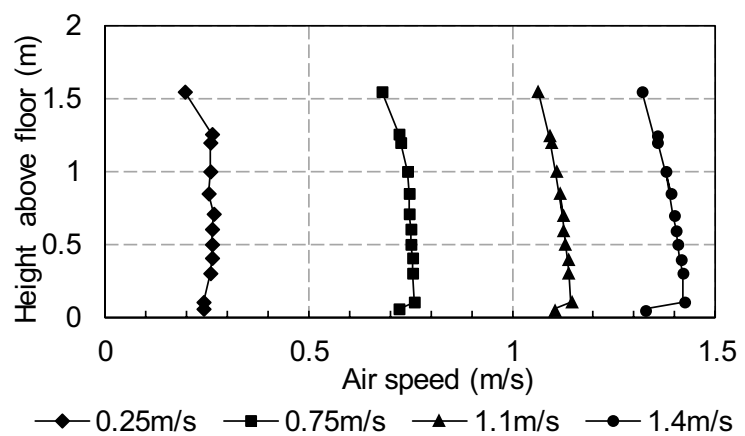

(a) Airspeed profile

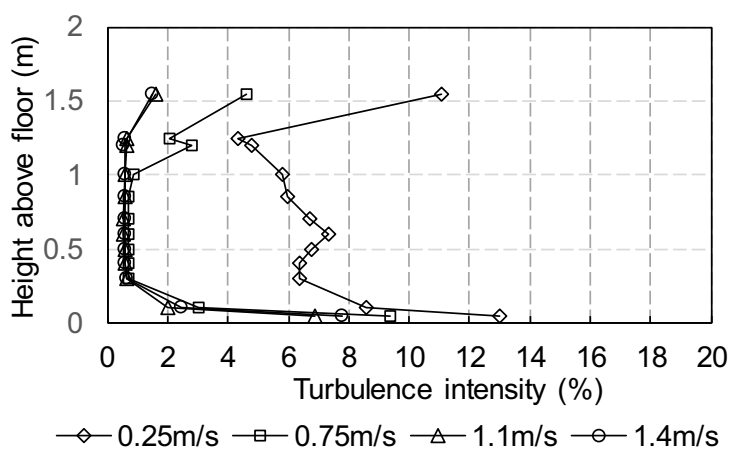

(b) Turbulence intensity profile

Fig. 5 Airspeed and turbulence intensity profiles

\subsection{Numerical method}

\subsubsection{Calm condition}

The commercial CFD code STAR-CCM+ Ver. 12.02 was utilized for CFD analysis. A geometry model (Fig. 6) was created referring to the shape of the climate chamber and the TM. The total and segments skin areas of the CTM and TM were almost identical. For the computational grid (Fig. 7), 20 layers of prisms with a growth rate of 1.13 and a thickness of $20 \mathrm{~mm}$ were created at the manikin surface to resolve the complex geometry and boundary layer of the CTM [12]. The $\mathrm{y}^{+}$ was below one everywhere on the manikin surface and wall surface. For other regions, tetrahedral cells were utilized.

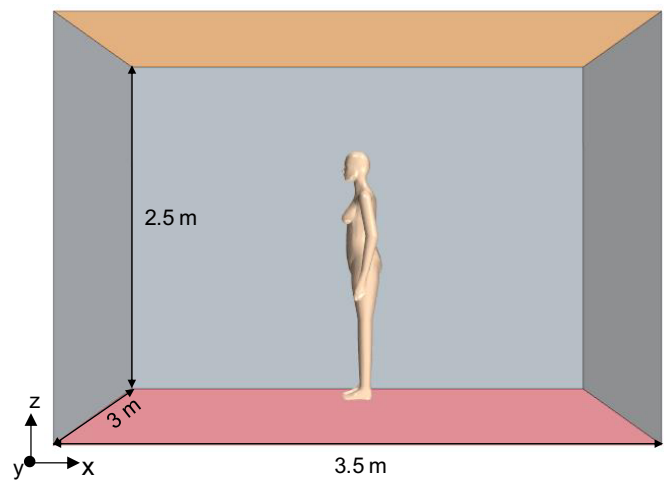

Fig. 6 Simulation model of climate chamber

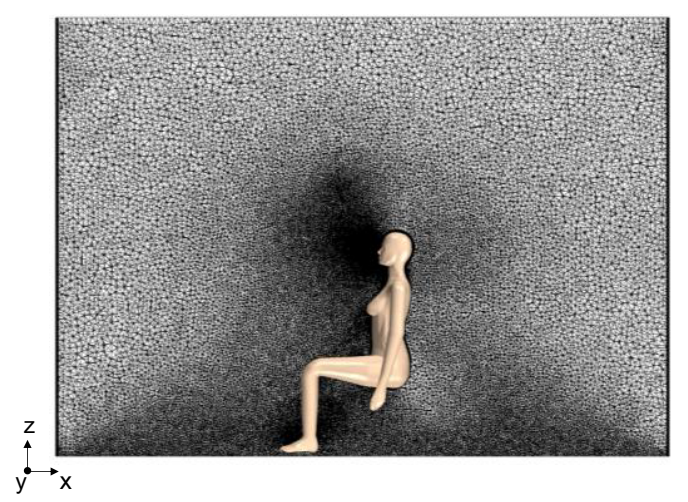

(a) Full view 


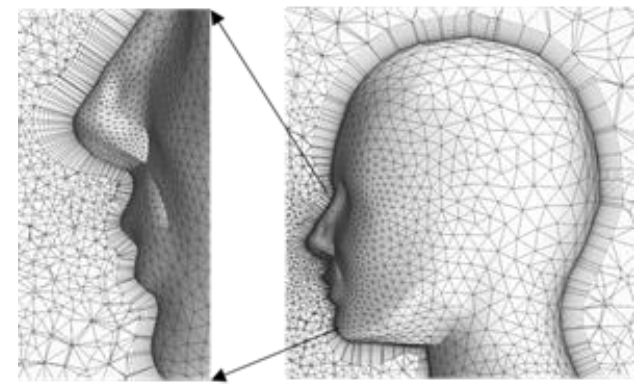

(b) Details at manikin surface

Fig. 7 Profile of the CFD mesh at the symmetry plane of the manikin

The flow and heat transfer were calculated with the Reynolds-averaged Navier-Stokes equations, which are closed by a Lien-Chen low Reynolds number $\mathrm{k}-\varepsilon$ model [13]. Low Reynolds number $\mathrm{k}-\varepsilon$ mode was verified to analyze accurately convective heat transfer around complicated geometry [14]. Since no wall functions have yet been devised for application of the standard kcturbulence model to complicated geometries such as the manikin, the only way to analyze the convective heat transfer with sufficient accuracy was to analyze the boundary layer flow near the skin surface with a locally fine grid and with low-Reynolds-number treatment. [15]. For the finite volume method, the second-order upwind difference scheme was utilized. The SIMPLE algorithm was used for the pressure-velocity coupling. Table 2 summarizes the details for the numerical method. The boundary conditions of the CFD analysis were set from the experiment. Table 3 details these boundary conditions.

Table 2 Numerical method

\begin{tabular}{|l|l|}
\hline \multirow{2}{*}{ Computational grid } & $\begin{array}{l}\text { Cell types: tetrahedral mesh, prism } \\
\text { layer }\end{array}$ \\
\cline { 2 - 2 } & $\begin{array}{c}\text { Number of cells: approximately 10 } \\
\text { million }\end{array}$ \\
\hline Turbulence model & $\begin{array}{l}\text { Standard low Reynolds number k- }-\varepsilon \\
\text { model }\end{array}$ \\
\hline Difference scheme & Second-order upwind \\
\hline Algorithm & SIMPLE \\
\hline Radiation & Surface-to-surface model \\
\hline
\end{tabular}

Table 3 Boundary conditions for calm condition

\begin{tabular}{|l|l|}
\hline Inlet (floor) & $\begin{array}{l}\text { Velocity: } U_{\text {in }} \text { (results of experiment) } \\
\text { Temperature: } t_{\text {in }} \text { (results of experiment) } \\
\text { Turbulence intensity: } k_{\text {in }}=0.1\end{array}$ \\
\hline $\begin{array}{l}\text { Outlet } \\
\text { (ceiling) }\end{array}$ & Pressure outlet $(\mathrm{P}=0)$ \\
\hline Wall & $\begin{array}{l}\text { Surface temperature: } t_{\text {wall }} \text { (results of } \\
\text { experiment) } \\
\text { Velocity: no slip }\end{array}$ \\
\hline
\end{tabular}

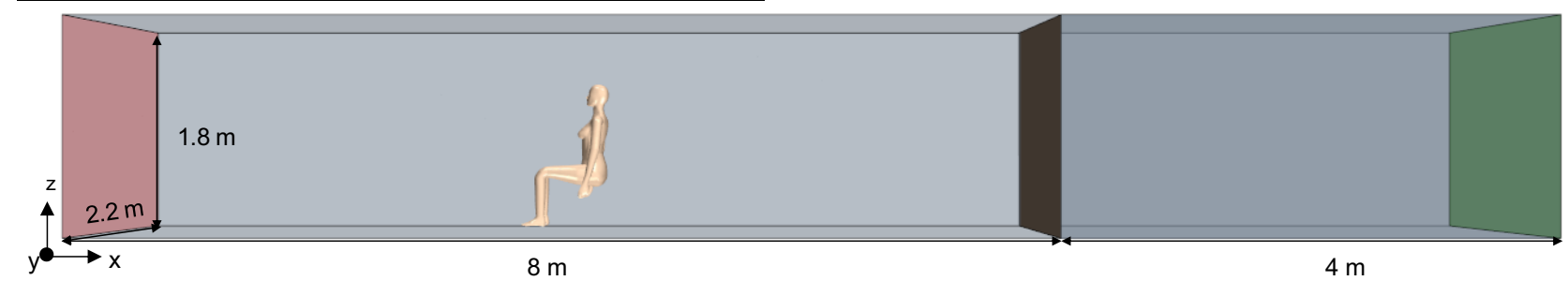

Fig. 8 Simulation model of wind tunnel

\begin{tabular}{|l|l|}
\hline TM & $\begin{array}{l}\text { Surface temperature: } 33{ }^{\circ} \mathrm{C} \\
\text { Velocity: no slip } \\
\text { Emissivity: } 0.95\end{array}$ \\
\hline
\end{tabular}

The numerical method for forced convection was the same as that for calm condition, except that the number of cells increased to approximately 20 million (shown in Table 2). A geometry model was created referring to the shape of the wind tunnel and TM (Fig. 8). The boundary conditions of the CFD analysis, which were based on the measured airspeeds and turbulence intensities for different height from floor (Fig. 5), are given in Table 4.

Table 4 Boundary conditions for forced convection model

\begin{tabular}{|l|l|}
\hline $\begin{array}{l}\text { Inlet (ABCD) } \\
\text { (Fig. 4) }\end{array}$ & $\begin{array}{l}\text { Velocity: } U_{\text {in }} \text { (results of experiment) } \\
\text { Temperature: } t_{\text {in }} \text { (results of experiment) } \\
\text { Turbulence intensity: } k_{\text {in }} \text { (results of } \\
\text { experiment) }\end{array}$ \\
\hline Outlet (EFGH) & $\begin{array}{l}U_{\text {out }} \text { free outflow velocity based on mass } \\
\text { conservation law }\end{array}$ \\
\hline Wall & $\begin{array}{l}\text { Surface temperature: } t_{\text {wall }} \text { (results of } \\
\text { experiment) } \\
\text { Velocity: no slip }\end{array}$ \\
\hline TM & $\begin{array}{l}\text { Direction: Front side, Back side, Right } \\
\text { side }\end{array}$ \\
\hline
\end{tabular}

\subsubsection{Radiation analysis}

Equations (3) and (4) reveal that sensible heat loss consists of radiative heat loss and convective heat loss. When measuring, it is difficult to separate the convective heat loss and radiative heat loss. Oguro et al. [10] assumed a uniform temperature field in which the surrounding wall surface temperatures were the same as the ambient air temperature, so $t_{a}$ and $\overline{t_{w}}$ were the same. Thus, $h_{c, i}$ and $h_{r, i}$ could be calculated via

$$
\begin{gathered}
q_{t, i}=q_{c, i}+q_{r, i}=h_{c, i}\left(t_{s, i}-t_{a}\right)+h_{r, i}\left(t_{s, i}-\overline{t_{w}}\right), \\
h_{r}=4 \sigma \varepsilon f_{\text {eff }}\left[273.15+\frac{t_{s, i}+t_{r}}{2}\right]^{3} .
\end{gathered}
$$

$\sigma:$ Stefan-Boltzmann constant, $5.68 \times 10^{-8} \mathrm{~W} /\left(\mathrm{m}^{2} \cdot \mathrm{K}^{4}\right)$ $\varepsilon$ : average emissivity of body surface, dimensionless However, this method requires the $f_{\text {eff }}$ term-effective radiation area factor for each body segment, and sometimes it is very difficult to ensure that the wall temperature and air temperature the same. De Dear [5] isolated the convective component of the total sensible heat transfer of the manikin by covering the surface of the TM with a very low emissivity coating, but this process was very labor intensive.

\subsubsection{Forced convection}


Fig. 9 shows the process used in this study to calculate $h_{c, i}$. The measured values of $\overline{t_{w}}$ and $t_{a}$ were used as boundary conditions, and when calculating the radiation, the flow solver was closed to avoid the effect of the fluid field. The surface-to-surface model was used for the radiation analysis [16]. The CTM surface and the walls of the chamber or wind tunnel were subdivided into contiguous patches on the base of the computational grid. Numerous beams were emitted from the center of each patch and traced through the computational field until they intercepted an opposing patch, thus defining a pair of patches that exchanged radiative energy. From this, view factors were calculated for each patch. At last the radiation energy transfer between the CTM and the wall could be calculated from the radiation transport equation and the boundary conditions.

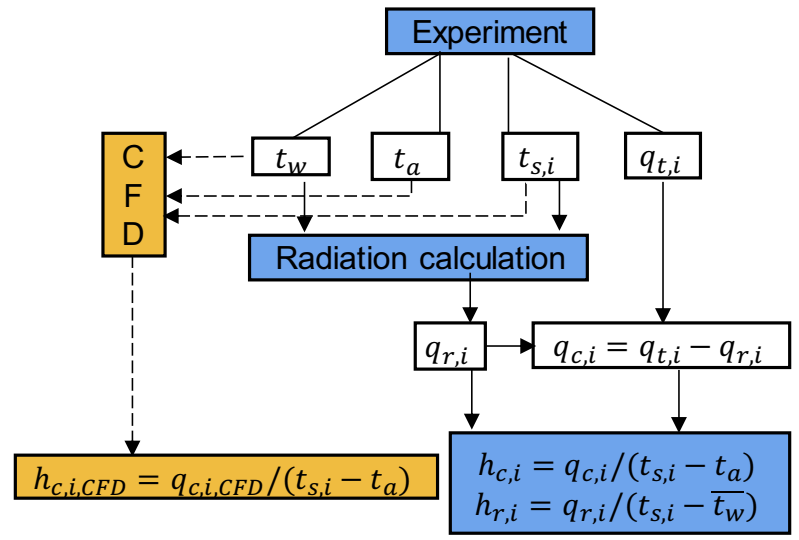

Fig. 9 Calculation process for $h_{c, i}$

$q_{c, i, C F D}:$ Convective heat loss through the skin of manikin segment $i$ according to CFD analysis, $\mathrm{W} / \mathrm{m}^{2}$

$h_{c, i, C F D}$ : Convective heat transfer coefficient for body segment $i$ for CFD analysis, $\mathrm{W} /\left(\mathrm{m}^{2} \cdot \mathrm{K}\right)$

\section{Results}

\subsection{Radiative heat transfer coefficient}

The radiative heat transfer coefficient was calculated with Eq. (4). The distribution of radiative heat transfer coefficients is given in Fig. 10. The radiative heat transfer coefficient between the arm and the torso is relatively small; likewise, the $h_{r}$ for the inner parts of the left and right thighs are smaller. This occurred because the view factors between these parts become smaller due to mutual occlusion. The $h_{r}$ for thighs in the sitting posture are smaller than those for the standing posture because the distance between the feet of the standing posture is much longer. Similarly, the $h_{r}$ for the arm in the standing posture is larger than that of sitting posture because the latter is more sheltered by the thigh. For the calm condition experiments, the convective and radiative heat transfer coefficient for the right and left sides of each body segment are averaged because the air environment is uniform. Fig. 11 and Table 5 show the values of the radiative heat transfer coefficient for different body segments under different ambient temperature conditions. The radiative heat transfer coefficients increase with ambient temperature. Values generally range from $4.5 \mathrm{~W} /\left(\mathrm{m}^{2} \cdot \mathrm{K}\right)$ to $6.0 \mathrm{~W} /\left(\mathrm{m}^{2} \cdot \mathrm{K}\right)$.

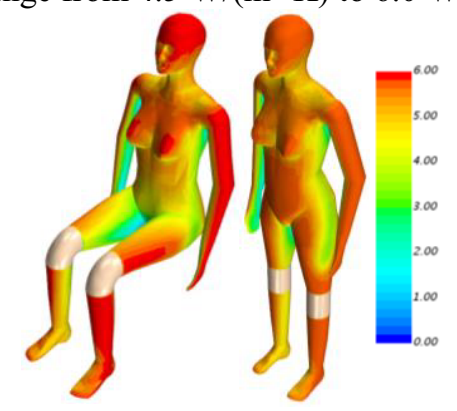

Fig. 10 Distribution of radiative heat transfer coefficient for an ambient temperature of $20{ }^{\circ} \mathrm{C}\left(\mathrm{W} /\left(\mathrm{m}^{2} \cdot \mathrm{K}\right)\right)$
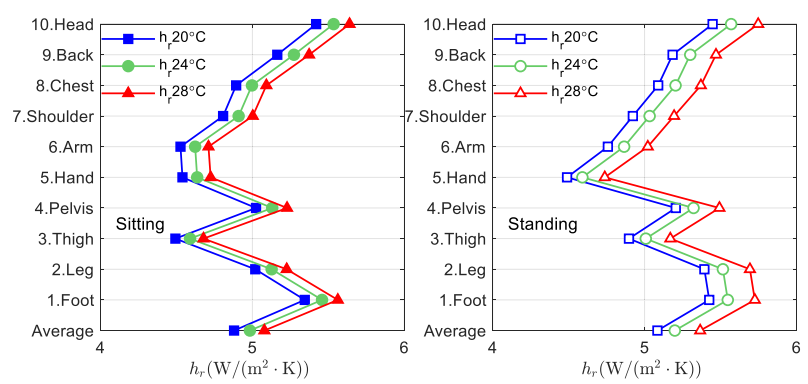

Fig. 11 Radiative heat transfer coefficient at different ambient temperatures $\left(\mathrm{W} /\left(\mathrm{m}^{2} \cdot \mathrm{K}\right)\right)$

Table 5 Radiative heat transfer coefficient for different segments under different ambient temperature $\left(\mathrm{W} /\left(\mathrm{m}^{2} \cdot \mathrm{K}\right)\right)$

\begin{tabular}{|c|c|c|c|}
\hline \multirow{2}{*}{ Segment } & $20^{\circ} \mathrm{C}$ & $24^{\circ} \mathrm{C}$ & $28^{\circ} \mathrm{C}$ \\
\hline & Sitting/Standing & Sitting/Standing & Sitting/Standing \\
\hline 10.Head & $5.42 / 5.45$ & $5.54 / 5.57$ & $5.64 / 5.75$ \\
\hline 9.Back & $5.16 / 5.18$ & $5.27 / 5.30$ & $5.37 / 5.47$ \\
\hline 8.Chest & $4.89 / 5.09$ & $5.00 / 5.20$ & $5.09 / 5.37$ \\
\hline 7.Shoulder & $4.81 / 4.92$ & $4.91 / 5.03$ & $5.00 / 5.19$ \\
\hline 6.Arm & $4.53 / 4.76$ & $4.62 / 4.87$ & $4.71 / 5.02$ \\
\hline 5.Hand & $4.54 / 4.49$ & $4.64 / 4.59$ & $4.73 / 4.74$ \\
\hline 4.Pelvis & $5.02 / 5.21$ & $5.13 / 5.32$ & $5.23 / 5.49$ \\
\hline 3.Thigh & $4.49 / 4.90$ & $4.59 / 5.01$ & $4.68 / 5.17$ \\
\hline 2.Leg & $5.02 / 5.39$ & $5.13 / 5.52$ & $5.23 / 5.69$ \\
\hline 1.Foot & $5.35 / 5.43$ & $5.45 / 5.55$ & $5.56 / 5.72$ \\
\hline Overall & $4.88 / 5.08$ & $4.98 / 5.20$ & $5.08 / 5.37$ \\
\hline
\end{tabular}

\subsection{Convective heat transfer coefficient}

\subsubsection{Effect of ambient temperature}

Fig 12 and Table 6 show the convective heat transfer coefficient for different segments of the human body. Because the air temperature near the TM $\left(t_{a(s)}\right)$ is slightly higher than the temperature of the air farther from the TM $\left(t_{a}\right)$ (Fig. 3), the $h_{c}$ calculated with $t_{a(s)}$ (Method A) are bigger than those calculated with $t_{a}$ (Method B). However, the $h_{c}$ calculated by the two methods are nearly equal because $t_{a}$ and $t_{a(s)}$ are almost the same in the CFD analysis. Therefore, in Fig 12 and Table 6, only the results from Method A for CFD analysis are listed. As for the effect of ambient temperature on $h_{c}$, as the ambient temperature increased, the $h_{c}$ decreased.

\footnotetext{
* Corresponding author: gaoshan@iis.u-tokyo.ac.jp
} 

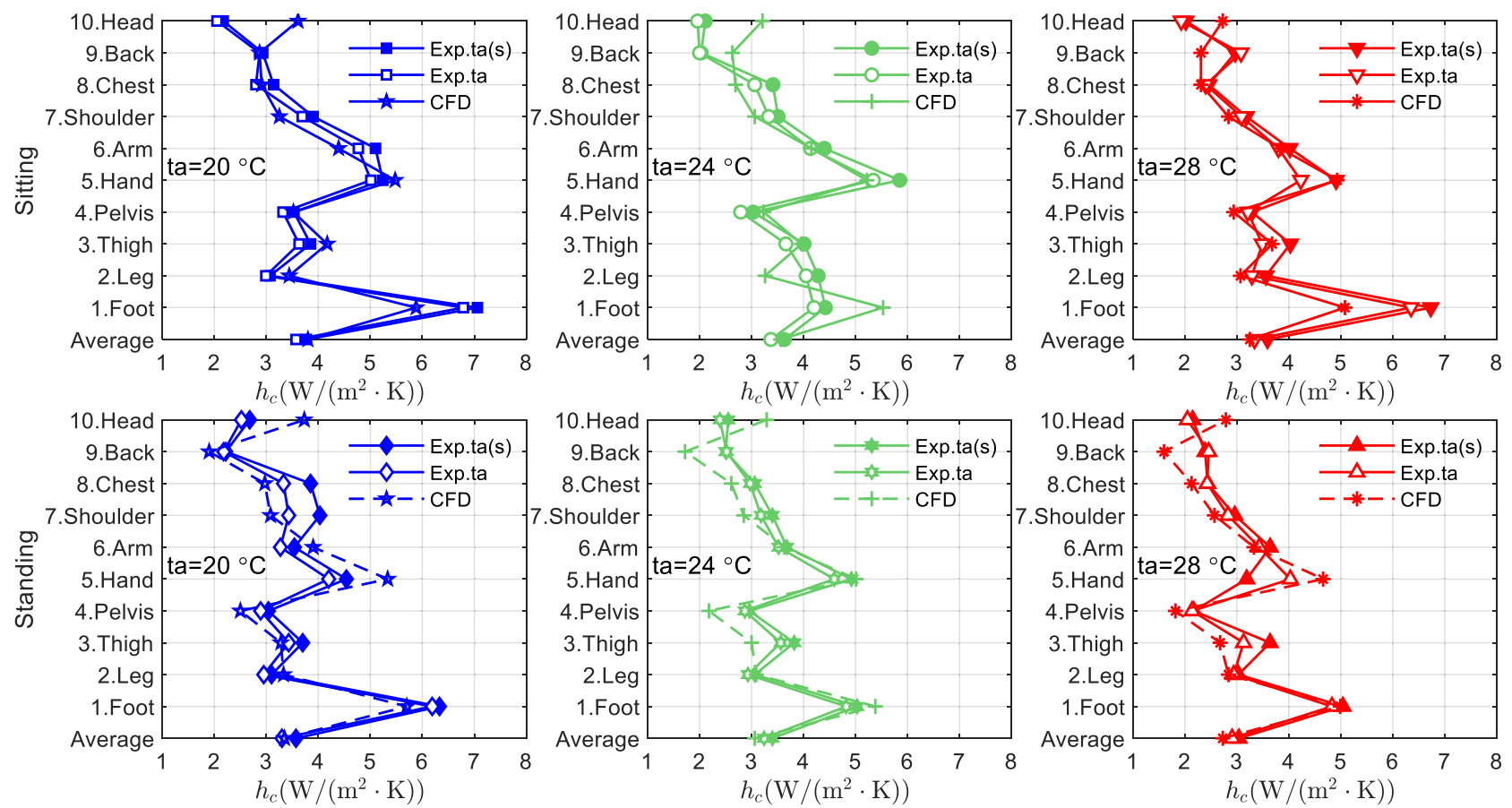

Fig 12 Convective heat transfer coefficients for each body segment under different ambient temperatures $\left(\mathrm{W} /\left(\mathrm{m}^{2} \cdot \mathrm{K}\right)\right)$

Table 6 Convective heat transfer coefficients for each body segment under different ambient temperatures $\left(\mathrm{W} /\left(\mathrm{m}^{2} \cdot \mathrm{K}\right)\right)$

\begin{tabular}{|c|c|c|c|c|c|c|c|c|c|c|c|c|}
\hline \multirow{3}{*}{ Segment } & \multicolumn{4}{|c|}{$20^{\circ} \mathrm{C}$} & \multicolumn{4}{|c|}{$24^{\circ} \mathrm{C}$} & \multicolumn{4}{|c|}{$28^{\circ} \mathrm{C}$} \\
\hline & \multicolumn{2}{|c|}{ Sitting } & \multirow{2}{*}{\multicolumn{2}{|c|}{$\begin{array}{l}\text { Standing } \\
\text { Exp./ CFD }\end{array}$}} & \multirow{2}{*}{\multicolumn{2}{|c|}{$\begin{array}{c}\text { Sitting } \\
\text { Exp./ CFD }\end{array}$}} & \multirow{2}{*}{\multicolumn{2}{|c|}{$\begin{array}{c}\text { Standing } \\
\text { Exp./ CFD }\end{array}$}} & \multirow{2}{*}{\multicolumn{2}{|c|}{$\begin{array}{c}\text { Sitting } \\
\text { Exp./ CFD }\end{array}$}} & \multirow{2}{*}{\multicolumn{2}{|c|}{$\begin{array}{c}\text { Standing } \\
\text { Exp./CFD }\end{array}$}} \\
\hline & Exp. & CFD & & & & & & & & & & \\
\hline \multirow{2}{*}{ 10. Head } & 2.17 & \multirow{2}{*}{3.61} & 2.68 & \multirow{2}{*}{3.73} & 2.11 & \multirow{2}{*}{3.21} & 2.55 & \multirow{2}{*}{3.29} & 2.02 & \multirow{2}{*}{2.73} & 2.15 & \multirow{2}{*}{2.79} \\
\hline & 2.05 & & 2.52 & & 1.96 & & 2.39 & & 1.93 & & 2.05 & \\
\hline \multirow{2}{*}{ 9. Back } & 2.93 & \multirow{2}{*}{2.87} & 2.22 & \multirow{2}{*}{1.90} & 2.03 & \multirow{2}{*}{2.63} & 2.50 & \multirow{2}{*}{1.72} & 2.97 & \multirow{2}{*}{2.31} & 2.39 & \multirow{2}{*}{1.60} \\
\hline & 2.87 & & 2.18 & & 2.00 & & 2.52 & & 3.08 & & 2.46 & \\
\hline \multirow{2}{*}{ 8. Chest } & 3.14 & \multirow{2}{*}{2.91} & 3.85 & \multirow{2}{*}{2.97} & 3.41 & \multirow{2}{*}{2.69} & 3.06 & \multirow{2}{*}{2.61} & 2.46 & \multirow{2}{*}{2.31} & 2.44 & \\
\hline & 2.8 & & 3.33 & & 3.06 & & 2.97 & & 2.40 & & 2.43 & 2.13 \\
\hline & 3.90 & & 4.03 & & 3.51 & & 3.40 & & 3.18 & & 2.96 & \\
\hline 7. Sh & 3.69 & 3.25 & 3.43 & 3.08 & 3.33 & 3.06 & 3.18 & 2.85 & 3.09 & 2.84 & 2.83 & 2.57 \\
\hline 6 Arm & 5.10 & 439 & 3.54 & 390 & 4.40 & 415 & 3.68 & 363 & 4.02 & 384 & 3.64 & 333 \\
\hline o. Arm & 4.77 & 4.39 & 3.27 & 3.90 & 4.13 & 4.15 & 3.52 & 3.65 & 3.80 & 3.84 & 3.43 & 3.35 \\
\hline & 5.24 & & 4.54 & & 5.85 & & 4.92 & & 4.91 & & 3.19 & \\
\hline 5. Hand & 5.01 & 5.48 & 4.2 & 5.33 & 5.34 & 5.22 & 4.59 & 5.01 & 4.23 & 4.93 & 4.03 & 4.66 \\
\hline & 3.53 & 352 & 3.04 & 2.50 & 3.03 & 323 & 2.96 & 218 & 3.29 & 294 & 2.17 & 182 \\
\hline 4 & 3.32 & 3.52 & 2.89 & & 2.79 & 3.23 & 2.87 & 2.18 & 3.21 & 2.94 & 2.14 & 1.82 \\
\hline & 3.85 & 417 & 3.70 & 3.28 & 4.01 & 396 & 3.82 & 300 & 4.03 & 68 & 2.55 & 268 \\
\hline n1gh & 3.63 & 4.17 & 3.43 & & 3.66 & 3.96 & 3.56 & 3.00 & 3.49 & 8 & 3.13 & 68 \\
\hline & 3.85 & & 3.10 & 3.33 & 4.28 & & 3.06 & 300 & 3.56 & & 3.03 & 34 \\
\hline Leg & 2.99 & 3.44 & 2.95 & & 4.05 & 3.26 & 2.93 & 09 & 3.29 & 1 & 2.94 & 34 \\
\hline & 7.06 & & 6.33 & & 4.42 & & 5.03 & & 6.73 & & 5.04 & \\
\hline 1. Foot & 6.79 & 5.88 & 6.19 & 5.70 & 4.20 & 5.53 & 4.82 & 38 & 6.35 & 8 & 4.83 & 99 \\
\hline & 3.77 & & 3.57 & & 3.63 & & 3.40 & & 3.59 & & 2.80 & \\
\hline C & 3.57 & 3. & 3.30 & 3 & 3.37 & 6 & 3.24 & 6 & 3.34 & 3.25 & 2.91 & 98 \\
\hline
\end{tabular}

For the experiment result, upside: data of taking $t_{a(s)}$ as reference temperature (Method A); downside: data of taking $t_{a}$ as reference temperature (Method B)

Table 7 shows the relative error estimation for the convective heat transfer coefficient $\left(h_{c}\right)$ calculated based on the different reference temperatures (Method A or Method B) compared to the CFD analysis calculated via

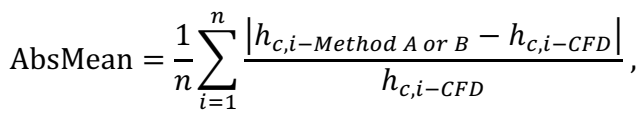

\footnotetext{
* Corresponding author: gaoshan@,iis.u-tokyo.ac.jp
} 
S. D.

$$
=\sqrt{\frac{1}{n} \sum_{i=1}^{n}\left(\frac{\left|h_{c, i-\text { Method } A \text { or } B}-h_{c, i-C F D}\right|}{h_{c, i-C F D}}-\text { AbsMean }\right)^{2}} \text {, }
$$

where $n=10$ is the number of body segments, $h_{c, i-M e t h o d} A$ or $B$ is the convective heat transfer coefficient for body segment $i$ calculated with Method A or $\mathrm{B}$, and $h_{c, i-C F D}$ is the convective heat transfer coefficient for body segment $i$ according to CFD

Table 7 Relative error estimation for $h_{c}$ calculated by different reference temperatures

\begin{tabular}{cccc}
\hline Posture & Statistic & $\begin{array}{c}\text { Method A } \\
\text { vs. CFD }\end{array}$ & $\begin{array}{c}\text { Method B } \\
\text { vs. CFD }\end{array}$ \\
\hline \multirow{2}{*}{ Sitting } & AbsMean & $13 \%$ & $14 \%$ \\
\multirow{2}{*}{ Standing } & S.D. & $11 \%$ & $11 \%$ \\
& AbsMean & $15 \%$ & $18 \%$ \\
& S.D. & $12 \%$ & $13 \%$ \\
\hline
\end{tabular}

These results indicate that the experiment results agree well with the CFD analysis results. The errors between the results of the two calculation methods and the CFD analysis results are approximately $10 \%$, but the error of Method A is smaller.

The regression equations for $h_{c}$ for calm condition are shown in Table 8 . The coefficients, $a$, of the regression equation for the sitting posture for all but the foot segment are larger than those of the standing posture. The coefficients for the feet, hands, arms, legs, and thighs are larger than those of the other body segments. In contrast, the exponents, $b$, of the regression equations for the standing posture are larger than the sitting posture, indicating that the $h_{c}$ of the standing posture change more rapidly with ambient temperature. The exponents for the head, back, chest, and pelvis are larger than those of the other body segment.
Table 8 Regression equations for $h_{c}$ for calm condition according to CFD analysis $\left(\mathrm{W} /\left(\mathrm{m}^{2} \cdot \mathrm{K}\right)\right)$

\begin{tabular}{|c|c|c|c|c|}
\hline \multicolumn{5}{|c|}{$h_{c}=a \cdot \Delta T^{b}$} \\
\hline \multirow{2}{*}{ Segment } & \multicolumn{2}{|c|}{ Sitting } & \multicolumn{2}{|c|}{ Standing } \\
\hline & $a$ & $b$ & $a$ & $b$ \\
\hline 10. Head & 1.71 & 0.29 & 1.71 & 0.30 \\
\hline 9. Back & 1.60 & 0.23 & 1.20 & 0.18 \\
\hline 8. Chest & 1.57 & 0.24 & 1.22 & 0.35 \\
\hline 7. Shoulder & 2.26 & 0.14 & 1.89 & 0.18 \\
\hline 6. Arm & 3.07 & 0.14 & 2.55 & 0.16 \\
\hline 5. Hand & 4.13 & 0.11 & 3.71 & 0.14 \\
\hline 4. Pelvis & 2.17 & 0.19 & 1.07 & 0.33 \\
\hline 3. Thigh & 2.98 & 0.13 & 1.91 & 0.21 \\
\hline 2. Leg & 2.54 & 0.12 & 2.17 & 0.16 \\
\hline 1. Foot & 3.97 & 0.15 & 3.99 & 0.14 \\
\hline Overall & 2.50 & 0.16 & 1.93 & 0.21 \\
\hline \multicolumn{5}{|c|}{$\mathrm{R}^{2}>0.99$ for all cases } \\
\hline
\end{tabular}

\subsubsection{Effect of air speed and wind direction}

Table 9 shows the convective heat transfer coefficient for each segment under different airspeeds and wind directions. Because the airspeed near each body segment varies, when deriving the regression model for each body segment, the measured airspeed was utilized. Finally, the whole-body regression model was derived from the regression models of all body segments, effectively removing the effect of uniform airspeed. The regression models for each body segment are of the form $h_{c}=a$. $v+b\left(\mathrm{~W} /\left(\mathrm{m}^{2} \cdot \mathrm{K}\right)\right)$, where $v$ is in $\mathrm{m} / \mathrm{s}$. This indicates that the convective heat transfer coefficient increases with airspeed. Table 9 confirms that when the right side of the TM is facing upwind, the intercept, $b$, and slope, $a$, of the right side become much larger than those of left side. However, when the TM is facing upwind or downwind, the $a$ and $b$ of the left and right sides are nearly identical.

Table 9. Regression equations for different airspeeds and wind directions $\left(\mathrm{W} /\left(\mathrm{m}^{2} \cdot \mathrm{K}\right)\right)$

\begin{tabular}{|c|c|c|c|c|c|c|c|c|c|c|c|c|}
\hline \multicolumn{13}{|l|}{$h_{c}=a \cdot v+b$} \\
\hline \multirow{3}{*}{ Segment } & \multicolumn{6}{|c|}{ Sitting } & \multicolumn{6}{|c|}{ Standing } \\
\hline & \multicolumn{2}{|c|}{$0^{\circ}$} & \multicolumn{2}{|c|}{$90^{\circ}$} & \multicolumn{2}{|c|}{$180^{\circ}$} & \multicolumn{2}{|c|}{$0^{\circ}$} & \multicolumn{2}{|c|}{$90^{\circ}$} & \multicolumn{2}{|c|}{$180^{\circ}$} \\
\hline & $a$ & $b$ & $a$ & $b$ & $a$ & $b$ & $a$ & $b$ & $a$ & $b$ & $a$ & $b$ \\
\hline 10. Head & 7.16 & 3.05 & 7.60 & 3.08 & 6.64 & 3.06 & 5.69 & 3.66 & 7.79 & 3.09 & 7.17 & 2.86 \\
\hline 9. Back & 5.00 & 2.09 & 5.23 & 1.72 & 5.22 & 4.23 & 6.24 & 1.41 & 5.65 & 1.51 & 5.70 & 4.35 \\
\hline 8. Chest & 5.88 & 3.72 & 6.23 & 2.91 & 6.36 & 1.33 & 3.85 & 4.13 & 6.03 & 2.86 & 7.96 & 0.88 \\
\hline 7. Shoulder(L) & 8.98 & 3.99 & 5.08 & 1.62 & 8.45 & 4.21 & 10.17 & 3.69 & 5.02 & 2.73 & 8.76 & 3.97 \\
\hline (R) & 9.06 & 3.99 & 7.78 & 4.09 & 8.42 & 4.21 & 8.06 & 4.30 & 8.42 & 3.91 & 8.75 & 3.96 \\
\hline 6. $\operatorname{Arm}(\mathrm{L})$ & 9.09 & 5.71 & 2.80 & 4.26 & 9.33 & 5.65 & 9.56 & 5.16 & 4.93 & 3.80 & 9.50 & 5.42 \\
\hline (R) & 9.23 & 5.70 & 9.98 & 5.07 & 9.35 & 5.65 & 8.16 & 5.51 & 9.91 & 4.87 & 9.53 & 5.42 \\
\hline 5. Hand(L) & 9.86 & 6.97 & 12.42 & 5.09 & 10.07 & 6.19 & 11.91 & 6.16 & 7.78 & 4.46 & 9.80 & 6.58 \\
\hline (R) & 10.07 & 6.85 & 1180 & 5.64 & 10.13 & 6.12 & 12.38 & 6.17 & 11.46 & 5.44 & 9.88 & 6.52 \\
\hline 4. Pelvis & 3.82 & 2.89 & 5.38 & 2.60 & 4.78 & 3.46 & 5.73 & 2.41 & 5.69 & 2.21 & 6.09 & 2.81 \\
\hline 3. Thigh(L) & 4.29 & 2.91 & 6.26 & 1.83 & 3.41 & 2.66 & 6.68 & 3.59 & 5.16 & 2.82 & 5.74 & 4.00 \\
\hline (R) & 4.42 & 2.81 & 5.98 & 3.63 & 3.41 & 2.64 & 6.01 & 3.87 & 6.55 & 5.00 & 5.75 & 3.91 \\
\hline 2. $\operatorname{Leg}(\mathrm{L})$ & 8.68 & 4.16 & 8.01 & 3.56 & 9.07 & 4.65 & 6.84 & 5.59 & 7.43 & 4.21 & 7.78 & 5.37 \\
\hline (R) & 8.36 & 4.28 & 9.19 & 4.77 & 8.99 & 4.64 & 7.71 & 5.43 & 8.38 & 5.02 & 7.81 & 5.35 \\
\hline 1. Foot(L) & 7.48 & 4.68 & 10.90 & 4.61 & 8.03 & 4.40 & 5.30 & 5.59 & 10.85 & 4.54 & 7.32 & 4.83 \\
\hline (R) & 7.54 & 4.67 & 10.23 & 5.49 & 7.96 & 4.48 & 6.68 & 5.20 & 10.44 & 5.46 & 7.98 & 4.78 \\
\hline Overall & 6.41 & 3.63 & 7.00 & 3.18 & 6.45 & 3.66 & 6.75 & 4.04 & 6.88 & 3.40 & 7.24 & 3.92 \\
\hline \multicolumn{13}{|c|}{$\mathrm{R}^{2}>0.96$ for all cases } \\
\hline
\end{tabular}




\section{Conclusion}

In this research, the effects of ambient temperature, airspeed, and wind direction on heat transfer around the human body were confirmed by experiment and CFD analysis. Our main results are as follows:

(1) For calm condition, the convective heat transfer coefficient tended to increase with the difference between skin temperature and air temperature (Fig. 13). The regression equations for the convective heat transfer coefficient for the whole body and the body segments were derived (Table 8 ). The whole-body convective heat transfer coefficient for the sitting posture is larger than that of standing posture because the body area facing the wind is larger. The radiative heat transfer coefficient for the whole body decreased slightly as the difference between skin temperature and ambient temperature increased for sitting posture and standing posture.

(2) For forced convection, there is no significant difference in the whole-body convective heat transfer coefficient caused by different wind directions for the sitting posture. However, the whole-body convective heat transfer coefficient for the standing posture caused by wind from the right side of the TM was smallest owing to the smaller surface area facing the wind. In addition, the convective heat transfer coefficient for the whole body for the sitting posture was smaller than the standing posture because some body segments shielded others from flow. The obtained results for the wholebody convective heat transfer are similar to those obtained by other researchers, as shown in Fig. 14.

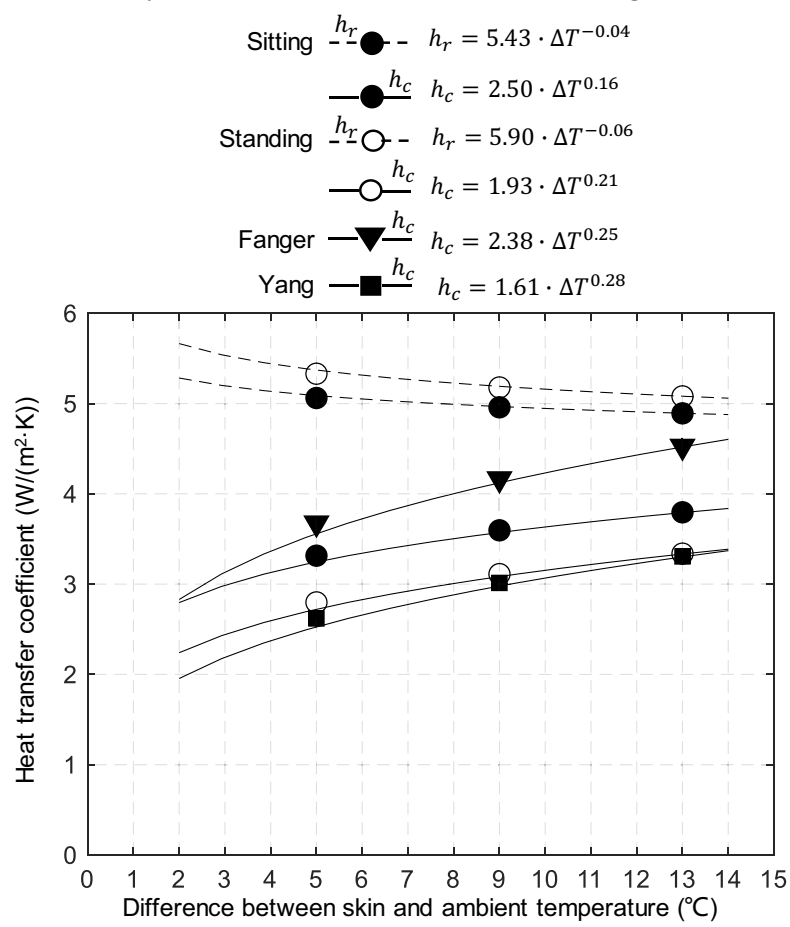

Fig. 13 Relationship between heat transfer coefficient and the difference between skin and ambient temperatures (Fanger[5], Yang[8])

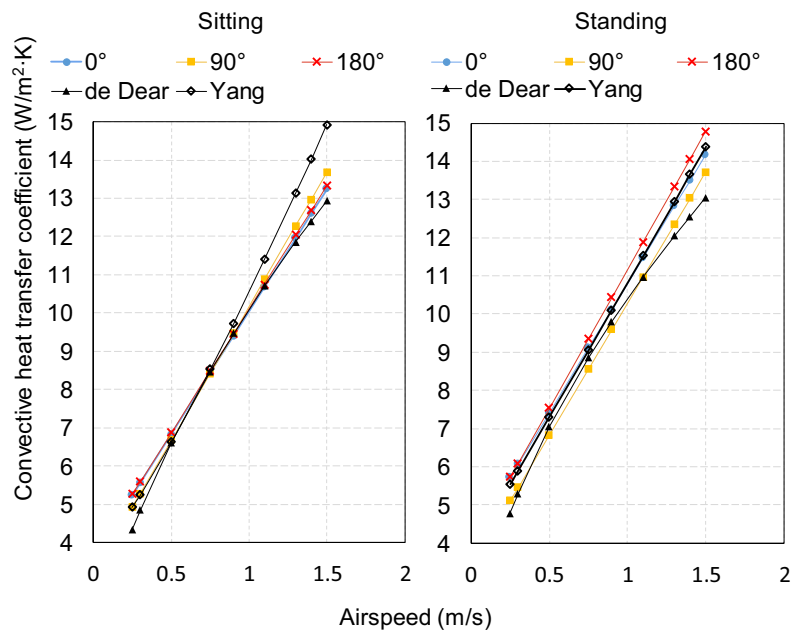

Fig 14 Comparison of whole-body convective heat transfer coefficient for sitting and standing postures for various airspeeds (de Dear [5], Yang[17])

\section{References}

1. in ASHRAE Handb. Fundam. (2017), p. 9.1-9.30.

2. P. Höppe, Energy Build. 34, 661 (2002).

3. P. O. Fanger, B. M. Ipsen, G. Langkilde, B. W. Olessen, N. K. Christensen, and S. Tanabe, Energy Build. 8, 225 (1985).

4. S. Tanabe, E. A. Arens, F. Bauman, H. Zhang, and T. Madsen, ASHRAE Trans 100 Part 1, 39 (1994).

5. R. J. De Dear, E. Arens, Z. Hui, and M. Oguro, Int. J. Biometeorol. 40, 141 (1997).

6. H. O. Nilsson, Build. Environ. 42, 4000 (2007).

7. T. Ono, S. Murakami, R. Ooka, and T. Omori, J. Wind Eng. Ind. Aerodyn. 96, 1719 (2008).

8. J.-H. Yang, S. Kato, T. Hayashi, and S. Murakami, J. Environ. Eng., AIJ (Transactions AIJ) 584, 33 (2004). 9. Y. Lu, F. Wang, X. Wan, G. Song, W. Shi, and C. Zhang, Int. J. Biometeorol. 59, 1475 (2015).

10. M. Oguro, E. Arens, R. Dear, Z. H, and T. Katayama, J Arch. Plann Env. Eng AIJ 67, 21 (2002).

11. ISO 7726:Ergonomics of the Thermal Environment -Instruments for Measuring Physical (1998).

12. P. V. Nielsen, F. Allard, L. B.Awbi, and A. Schalin, Computational Fluid Dynamics in Ventilation Design. REHVA Guidebook No. 10 (2007).

13. W. L. Chen, F. S. Lien, and M. A. Leschziner, Int. J. Heat Fluid Flow 19, 297 (1998).

14. S. Murakami, S. Kato, and J. Zeng, Build. Environ. 35, 489 (2000).

15. S. Murakami, S. Kato, and J. Zeng, in TsinghuaHVAC'95. (1995), pp. 349-354.

16. STAR-CCM+ User Guide - Version 12.02 (2017). 17. J. Yang, S. Kato, and J. Seo, J. Asian Archit. Build. Eng. 8, 563 (2009).

\footnotetext{
* Corresponding author: gaoshan@iiis.u-tokyo.ac.jp
} 